\title{
Visual communication stimulates reproduction in Nile tilapia, Oreochromis niloticus (L.)
}

\author{
A.L.S. Castro ${ }^{1,2,5}$, E. Gonçalves-de-Freitas ${ }^{1,2,5}$, G.L. Volpato ${ }^{1,3,5}$ and C. Oliveira1,4 \\ 1 Universidade Estadual Paulista (UNESP) and Centro de Aquicultura da UNESP (CAUNESP), Brasil \\ ${ }^{2}$ Laboratório de Comportamento Animal, Departamento de Zoologia e Botânica, Instituto de Biociências, \\ Letras e Ciências Exatas, UNESP, São José do Rio Preto, SP, Brasil \\ ${ }^{3}$ Laboratório de Fisiologia e Comportamento Animal, Departamento de Fisiologia, UNESP, \\ Botucatu, SP, Brasil \\ ${ }^{4}$ Laboratório de Anatomia Comparada, Departamento de Biologia, Instituto de Biociências, Letras e \\ Ciências Exatas, UNESP, São José do Rio Preto, SP, Brasil \\ ${ }^{5}$ Research Center on Animal Welfare, CNPq Multi-University Group, Brasil \\ Correspondence to: E. Gonçalves-de-Freitas, Departamento de Zoologia e Botânica, IBILCE, UNESP, \\ R. Cristóvão Colombo, 2265, 15054-000 São José do Rio Preto, SP, Brasil \\ E-mail: elianeg@ibilce.unesp.br
}

\begin{abstract}
Reproductive fish behavior is affected by male-female interactions that stimulate physiological responses such as hormonal release and gonad development. During male-female interactions, visual and chemical communication can modulate fish reproduction. The aim of the present study was to test the effect of visual and chemical male-female interaction on the gonad development and reproductive behavior of the cichlid fish Nile tilapia, Oreochromis niloticus (L.). Fifty-six pairs were studied after being maintained for 5 days under one of the four conditions ( $N=14$ for each condition): 1 ) visual contact ( $V$ ); 2) chemical contact $(\mathrm{Ch})$; 3) chemical and visual contact $(\mathrm{Ch}+\mathrm{V})$; 4) no sensory contact (Iso) - males and females isolated. We compared the reproductive behavior (nesting, courtship and spawning) and gonadosomatic index (GSI) of pairs of fish under all four conditions. Visual communication enhanced the frequency of courtship in males (mean \pm SEM; V: $24.79 \pm 3.30, C h+V: 20.74 \pm 3.09$, Ch: 0.1 \pm 0.07 , Iso: $4.68 \pm 1.26$ events/30 min; $P<0.05$, two-way ANOVA with LSD post hoc test), induced spawning in females (3 spawning in $\mathrm{V}$ and also 3 in $\mathrm{Ch}+\mathrm{V}$ condition), and increased $\mathrm{GSI}$ in males (mean $\pm \mathrm{SEM}$; $\mathrm{V}: 1.39 \pm 0.08, \mathrm{Ch}+\mathrm{V}: 1.21 \pm 0.08, \mathrm{Ch}$ : $1.04 \pm 0.07$, Iso: $0.82 \pm 0.07 \% ; P<0.05$, two-way ANOVA with LSD post hoc test). Chemical communication did not affect the reproductive behavior of pairs nor did it enhance the effects of visual contact. Therefore, male-female visual communication is an effective cue, which stimulates reproduction among pairs of Nile tilapia.
\end{abstract}

Key words: Courtship; Cichlid; Gonadosomatic index; Visual cues; Chemical cues

Research supported by CNPq (\#130503/03-7 and \#302022/2006-6), PROPE-UNESP (\#1306/50/1/2001) and FUNDUNESP (\#557-01-DCP). Publication supported by FAPESP.

Received February 23, 2008. Accepted January 26, 2009

\section{Introduction}

The reproductive behavior of many fish species involves a complex courtship that facilitates sexual recognition, supplies information about reproductive conditions of the mate, stimulates reproduction, and synchronizes spawning $(1,2)$. During male-female interactions, pairs use different sensorial cues, which affect their reproductive behavior and gonadal state. In Oncorhynchus species, for example, visual and mechanical cues from females induce spermiation in males (3). The sound produced by some species facilitates intraspecific recognition and accelerates spawning $(4,5)$, whereas sighting a male increases ovulation frequency in female Oreochromis mossambicus 
(6), Trichogaster trichopterus (7), and Danio rerio (8).

Pheromones often are sensorial ways for modulating reproduction in fish (9). In cyprinids, the pheromone 4pregnen-17 $\alpha, 20 \beta$-diol-3-one $(17,20 \beta \mathrm{P})$ delivered by female urine synchronizes spawning and enhances sperm production (10).

Vision is well developed in the cichlid fish species (11) and visual communication is an important part of their reproductive interaction (e.g., 12). However, chemical communication has also been reported for cichlids as an important way for reproductive communication (e.g., 13,14). In the cichlid Nile tilapia, Oreochromis niloticus, the dominant male increases chasing and courtship of females injected with 17,20ßP, but in anosmic males these behaviors are not demonstrable (15). However, the background color of a substrate modulates the frequency of spawning in Nile tilapia (16) and the species shows elaborated courtship movements (17), suggesting that visual communication is part of its reproductive behavior.

The presence of females in a group of Nile tilapia stimulates males to build nests (18). Although this indicates the effect of the opposite sex on reproductive behaviors, the specific stimuli taking part in male-female interaction (chemical, visual, or both) are unknown. Because such effects are probably genetically determined, understanding the relative importance of sensorial modalities in Nile tilapia reproduction may help control the reproduction of this species for research and aquaculture.

The objective of the present study was to test the effect of visual and chemical cues on the reproductive behavior of Nile tilapia. This species establishes a social hierarchy in which dominant males take priority for mating. They build circular nests (spawning site) by mouth digging, defend the nests against intruders, court females, and mate inside the nests (17). Nile tilapias are mouthbrooders, a female behavior that includes caring for eggs and larvae by holding them inside her mouth (19). We analyzed the effect of visual and chemical cues on courtship, nest building, and spawning. Since the male-female interaction can also affect the gonad state of the fish (1), we also investigated the effect of visual and chemical cues on male and female gonad development.

\section{Material and Methods}

We tested the effects of male and female visual and chemical communication on the reproduction of Nile tilapia under four sensorial conditions: visual, chemical, chemical and visual, and no sensorial contact (males completely isolated from females). The reproductive behavior and gonadosomatic index (GSI $=100 \times$ gonad weight $/$ body weight) were determined to assess the effect of visual stimuli on the reproductive behavior of the species.

\section{Holding conditions and general procedures}

Adult Nile tilapias were purchased from a commercial supplier and held in outdoor ponds under natural conditions of temperature and photoperiod. Before the experiments, the fish were acclimated to laboratory conditions in 500-L asbestos tanks ( 1 fish $/ 5 \mathrm{~L} ; 27^{\circ} \mathrm{C}$; 12 -h light/dark cycles, starting at 7:00 am) for at least 20 days. The fish were overfed with a tropical fish ration (commercial pellets, $28 \%$ protein) twice a day.

The fish were removed from the holding tanks, anesthetized with benzocaine (128 mg/L), weighed, sized, and sexed by staining the genital papillae with methylene blue, which shows the opening of the female oviduct (20).

Little et al. (21) reported that 5 days of social interaction are sufficient to induce spawning in Nile tilapia. However, a control group of completely isolated fish was also required because isolation is known to induce gonad regression in another cichlid species (22). Thus, we conducted a preliminary study to test the effect of isolation on GSI. This experiment was necessary to ensure that the effects of sensory treatments could be attributed to the stimulatory effects of visual and chemical cues, rather than to inhibitory effects of social isolation.

Table 1. Standard length, body weight and gonadosomatic index (GSI) of male and female Nile tilapia after 5-day isolation (Experiment 1).

\begin{tabular}{|c|c|c|c|c|c|c|}
\hline & \multicolumn{3}{|c|}{ Male } & \multicolumn{3}{|c|}{ Female } \\
\hline & Length (cm) & Body weight $(\mathrm{g})$ & GSI (\%) & Length (cm) & Body weight (g) & GSI (\%) \\
\hline Isolated & $10.60 \pm 0.28$ & $42.25 \pm 3.16$ & $0.69 \pm 0.07$ & $10.42 \pm 0.22$ & $40.26 \pm 3.16$ & $3.07 \pm 0.33$ \\
\hline Non-isolated (from tanks) & $10.69 \pm 0.17$ & $44.81 \pm 2.18$ & $0.61 \pm 0.09$ & $10.48 \pm 0.23$ & $44.29 \pm 2.99$ & $3.34 \pm 0.35$ \\
\hline
\end{tabular}

Data are reported as mean \pm SEM for 8 pairs of fish in each group. There were no statistical differences between groups (independent $t$-test). 
Experiment 1: isolation and gonad development

Isolated and non-isolated fish (from 500 L-holding tanks) were compared to test the effect of isolation on gonad regression. Eight males and eight females (Table 1) were taken randomly and gonads were obtained immediately, to calculate GSI, a reliable indicator of gonad development for male and female Nile tilapia (23). At the same time, 8 males and 8 females were caught and maintained completely isolated in glass aquaria $\left(40 \times 30 \times 40 \mathrm{~cm} ; 27^{\circ} \mathrm{C}\right.$; $12-$ $\mathrm{h}$ light/dark cycles, starting at 7:00 am) for 5 days. After this period, GSI was measured.

GSI was not affected by the 5-day isolation (Table 1). Thus, the isolated treatment was used as the control condition in Experiment 2.

Experiment 2: sensorial cues and stimulation of reproductive condition

This experiment was conducted immediately after Experiment 1 to assess the role of visual and/or chemical communication on stimulation of reproductive condition in Nile tilapia. The fish were maintained under one of the four treatments designed for behavioral observations for 5 days. Each treatment included 14 pairs of fish and is described below. Fish in all treatments were similar in size and weight (Table 2).

Visual communication (V): 1 male and 1 female of two contiguous aquaria could see each other, no other contact was allowed. Each compartment of the experimental aquaria measured $30 \times 40 \times 40 \mathrm{~cm}$ (and contained about $48 \mathrm{~L}$ ).

Chemical communication (Ch): a larger aquarium was divided into two compartments of the same size, following the criterion of equivalent compartment sizes of the other treatments. An opaque partition divided this aquarium and prevented visual male-female communication. Chemical communication was allowed by water circulation between compartments, through three holes $(1.5 \mathrm{~cm}$ in diameter) near the bottom. Small pipes placed in the holes inhibited visual contact. Water circulated continuously by an aeration system ( 3 L/min) whose efficiency was demonstrated by transferring water mixed with methylene blue from one compartment to the other.

Chemical + visual communication $(C h+V)$ : this and the previous treatment were similar, except that here a transparent partition divided the aquarium into two compartments.

Isolation (Iso): aquaria receiving male or female fish isolated from any communication with conspecifics.

Lateral and posterior walls of the aquaria were covered with an opaque blue plastic to prevent undesired visual contact with the fish in adjacent aquaria. Blue is known to reduce stress (24) and improve reproduction (16) in Nile tilapia. Water temperature was maintained at $27 \pm 1^{\circ} \mathrm{C}$ by individual thermostats and the photoperiod was 12-h light/dark cycles, starting at 7:00 am. Aquaria bottoms were covered with a $3.0-\mathrm{cm}$ layer of gravel to allow nesting. The fish were fed an amount equivalent to $2 \%$ of their body weight twice a day, $1 \mathrm{~h}$ after lights were turned on and $1 \mathrm{~h}$ before lights were turned off. A biological filter preserved water quality in each aquarium during the experiment, with ammonia and nitrite kept lower than $0.25 \mathrm{ppm}$ and $0.025 \mathrm{ppm}$, respectively.

\section{Analysis of behavior}

The fish were video-recorded for the analysis of behavior (15 min/day) on the $2 \mathrm{nd}$ and 4 th days, from $1-5 \mathrm{pm}$ because the highest reproductive activity in this species occurs in the afternoon (17). The frequency of undulation was recorded because this is a known courtship-related behavior among Nile tilapia (17) and other related species (12). Undulation occurs when the fish beats its tail sideways, thus undulating its body.

The aquaria were examined daily, at the beginning of the light period and just before its end, to record spawning (revealed by female mouthbrooding) and nest occurrence. Male tilapias excavate the gravel from the bottom with their mouth, making circular nests $(17,19)$. At the end of the experiment, the diameter and length of nests we measured and elliptical areas of nests were calculated. When two nests were found in the same aquarium, their areas were summed to indicate fish investment in nesting. This measurement permitted us to test the association between sensorial condition and nesting behavior.

\section{Gonads}

After 5 days of pairing, the fish received a lethal dose of

Table 2. Standard length and body weight of male and female Nile tilapia used in different sensorial contacts (Experiment 2).

\begin{tabular}{lcclll}
\hline Sensorial cues & \multicolumn{2}{c}{ Male } & & \multicolumn{2}{c}{ Female } \\
\cline { 2 - 3 } \cline { 6 - 7 } & Length $(\mathrm{cm})$ & Weight $(\mathrm{g})$ & & Length $(\mathrm{cm})$ & Weight $(\mathrm{g})$ \\
\hline Visual & $10.14 \pm 0.07$ & $36.09 \pm 1.01$ & & $9.90 \pm 0.11$ & $34.27 \pm 1.38$ \\
Chemical + visual & $10.25 \pm 0.07$ & $37.57 \pm 0.87$ & & $9.95 \pm 0.14$ & $33.92 \pm 1.40$ \\
Chemical & $10.32 \pm 0.11$ & $37.57 \pm 1.28$ & & $9.94 \pm 0.13$ & $34.53 \pm 1.33$ \\
Isolated & $10.30 \pm 0.10$ & $37.28 \pm 1.18$ & & $9.75 \pm 0.12$ & $32.96 \pm 1.34$ \\
One-way ANOVA & $\mathrm{F}_{(3,52)}=0.78$ & $\mathrm{~F}_{(3,52)}=0.93$ & & $\mathrm{~F}_{(3,52)}=0.54$ & $\mathrm{~F}_{(3,52)}=0.25$
\end{tabular}

Data are reported as mean \pm SEM for 14 pairs of fish for each sensorial cue. There were no statistical differences between groups (one-way ANOVA). 
the anesthetic benzocaine and fish were then sized and weighed, and their gonads collected for GSI calculation (as in Experiment 1). Testes and ovaries were fixed in Bouin solution and preserved in $70 \%$ alcohol for histology. Eight pairs from each experiment were randomly selected for gonad histology (gonads embedded in paraplast to make permanent slides). We made 3 and $5 \mu \mathrm{m}$ cuts in eggs and $3 \mu \mathrm{m}$ cuts in testes, and used hematoxylin-eosin staining. The aim of this analysis was to compare gonad maturation stages among experiments.

\section{Statistical analysis}

Data were tested for normality by Shapiro Wilk's test (25). Treatments were compared separately for males and females. Nest areas were compared among treatments by one-way ANOVA completed with the LSD post hoc test, and nest frequency was assessed by the chi-square test (25). The frequency of undulation and GSI were analyzed by two-way ANOVA completed with the LSD post hoc test (25), considering all four sensorial conditions and the males that built nests and those that did not.

\section{Taxonomy and ethical considerations}

Five samples of fish used in this experiment were identified as Oreochromis niloticus and deposited in the Zoological Collection of Department of Zoology and Botany, IBILCE, UNESP, São José do Rio Preto, under the supervision of Dr. Francisco Langeani Neto. This study was conducted in agreement with the precepts of the Brazilian College for Animal Experimentation (COBEA, Colégio Brasileiro de Experimentação Animal; www.cobea.org.br).

\section{Results}

Effect of sensorial cues on nesting and spawning

Nesting occurred in all treatments, and nests were similar in area and frequency (Table 3). Despite literature

Table 3. Nesting behavior of Nile tilapia as a function of sensorial cues.

\begin{tabular}{lccccr}
\hline $\begin{array}{l}\text { Sensorial } \\
\text { conditions }\end{array}$ & \multicolumn{3}{c}{ Male } & & \multicolumn{2}{c}{ Female } \\
\cline { 2 - 3 } \cline { 5 - 6 } & $\begin{array}{c}\text { Nesting relative } \\
\text { frequency }^{a}\end{array}$ & $\begin{array}{c}\text {Nest area }^{\mathrm{b}} \\
\left(\mathrm{cm}^{2}\right)\end{array}$ & & $\begin{array}{c}\text { Nesting relative } \\
\text { frequency }\end{array}$ & $\begin{array}{c}\text { Nest areab }^{\mathrm{b}} \\
\left(\mathrm{cm}^{2}\right)\end{array}$ \\
\hline Visual & 0.43 & $158.7 \pm 24.29$ & & 0.57 & $85.3 \pm 12.94$ \\
Chemical + visual & 0.43 & $269.3 \pm 52.97$ & & 0.29 & $159.7 \pm 34.18$ \\
Chemical & 0.57 & $310.9 \pm 48.67$ & & 0.29 & $107.5 \pm 26.59$ \\
Isolated & 0.43 & $139.7 \pm 18.44$ & & 0.29 & $139.3 \pm 18.39$ \\
\hline
\end{tabular}

Data are reported as mean \pm SEM for 14 pairs of fish for each condition. There were no statistical differences among sensorial conditions ( ${ }^{\mathrm{a}} \mathrm{chi}$-square test; ${ }^{\mathrm{b}}$ one-way ANOVA). reports that only males dig nests, both males and females built nests. Spawning occurred only in treatments with visual communication between males and females ( $V$ and $\mathrm{Ch}+\mathrm{V} ; 3$ spawnings each). In all 6 spawns both males and females built a nest. In three cases, males and females built a half-nest in each compartment. The halves were near one another at the compartment partition, forming a complete circular nest.

\section{Effect of sensorial cues on courtship behavior}

Because nests were not built in some of the experiments, we compared the effect of treatment on undulation behavior among replicates where males built and those where they did not build nests, using a two-way ANOVA.

There was no statistical interaction between male nest building and treatment $\left(F_{(3,48)}=0.73, P=0.53\right)$ and no effect of investment on nesting $\left(F_{(1,48)}=2.71, P=0.11\right)$. However, the sensory treatments significantly affected the frequency of male undulations, a component of courtship behavior $\left(F_{(3,48)}=23.61, P=0.0001\right)$. Undulation frequencies of male $\mathrm{V}$ and $\mathrm{V}+\mathrm{Ch}$ fish were similar $(\mathrm{P}=0.21$, LSD test) but significantly larger than $\mathrm{Ch}(\mathrm{P}<0.0001)$ and Iso fish $(P<0.0001)$.

The same procedure was used for females, with similar results. There was no statistical interaction between female nest building and treatment $\left(\mathrm{F}_{(3,48)}=0.24, \mathrm{P}=0.87\right)$ and no nesting effect $\left(F_{(1,48)}=0.55, P=0.46\right)$. The sensory treatment significantly affected the frequency of female undulations $\left(\mathrm{F}_{(3,48)}=8.69, \mathrm{P}=0.0001\right)$. Undulation frequencies of female $\mathrm{V}$ and $\mathrm{V}+\mathrm{Ch}$ fish were similar $(\mathrm{P}=0.84$, LSD test), but significantly larger than $C h(P<0.001)$ and Iso fish $(P<0.001)$. Figure 1 shows undulation data grouped by treatments because there was no effect of nest building on this variable.

\section{Effect of sensorial cues on gonads}

Fish that spawned were not included in the GSI analysis because gonad weight is reduced after spawning (23). We determined if spawning had occurred by the presence of eggs in the female's mouth, but we could not observe spermiation by males. However, we excluded from GSI analysis three malefemale pairs from the $V$ treatment and three pairs from the $\mathrm{Ch}+\mathrm{V}$ treatment, with 11 pairs remaining in each of these treatments, in order to avoid an effect of reduced GSI on them.

Differences between the GSI of males that built or did not build nests were detected. Of the four $\mathrm{Ch}+\mathrm{V}$ females that built 
nests, three also spawned. After excluding spawned females, we had only one pair, which did not allow us to include it in the statistical analysis, but the GSI values are shown in Figure 2B.

Two-way ANOVA indicated the effects of treatment $\left(F_{(3,42)}=4.05, P=0.01\right)$ and nest building $\left(F_{(1,42)}=13.25, P=0.0007\right)$ on male GSI, and no interaction effect $\left(F_{(3,42)}=2.38, P=0.08\right.$; Figure $\left.2 A\right)$. According to the LSD post hoc test, GSI was higher for males that built nests ( $P=$ 0.0006 , LSD test). However, the GSI of males that built nests was lower in Iso and Ch conditions than in $\mathrm{V}$ and $\mathrm{Ch}+\mathrm{V}(\mathrm{P}<$ 0.02 ; Figure $2 \mathrm{~A}$ ). No significant GSI differences were found for females in any of the treatments $\left(F_{(2,32)}=1.06, P=0.35\right.$; Figure 2B).

According to the histological analyses of gonads, all fish were mature and ready for reproduction, independent of gender or experimental treatment. Testes showed spermatic cells in different stages and forming a line in the seminiferous tube, which contained a large number of free spermatozoids. Ovaries showed oocytes in different stages of development and several large and mature oocytes in full vitellogenesis activity.

\section{Discussion}

This study showed that visual communication between sexual partners modulates reproductive behavior of Nile tilapia, both stimulating courtship and gonad development in males and spawning in females. This is supported by the spawning frequency, courtship behavior, and GSI of males that build nests, which are documented here.

Male and female nest digging was observed irrespective of treatment. According to Lowe-McConnell (19), only males of Nile tilapia build nests in natural environments. However, Gonçalves-de-Freitas and Nishida (17) observed that after females were driven to the nests by males, females worked to increase nest size. In the present study, isolated females also

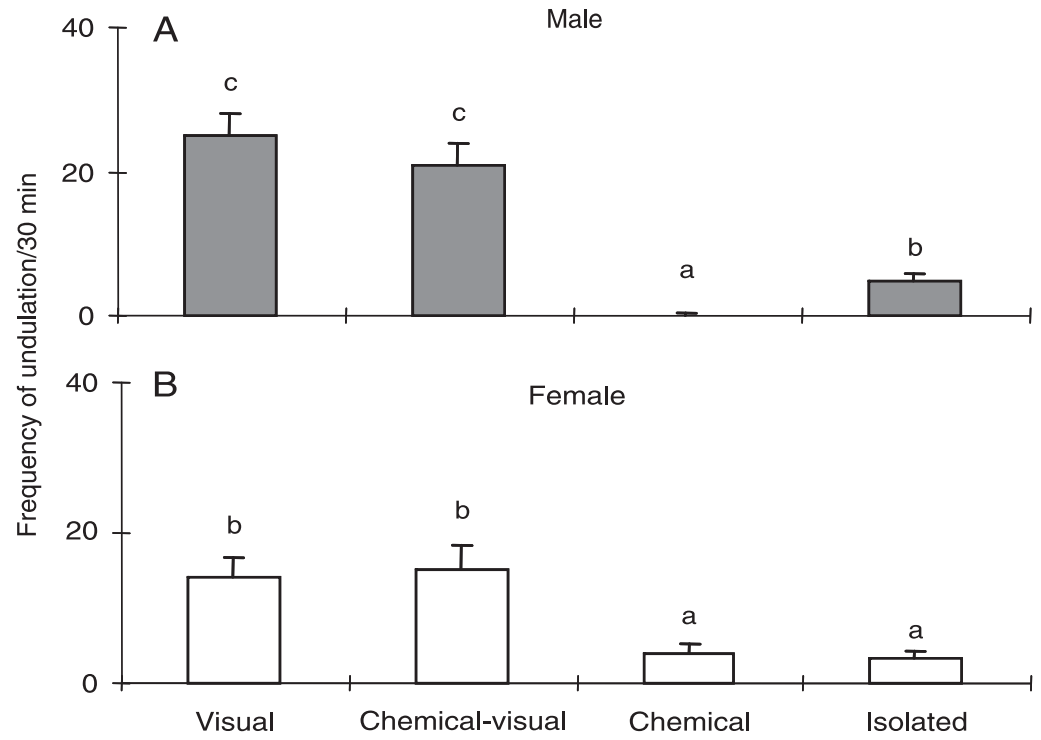

Figure 1. Undulation frequency of males and females under four sensorial conditions ( $N=14$ pairs in each condition). Data are reported as means $\pm S E M$. Different letters indicate statistically significant differences compared with other groups $(\mathrm{P}<$ 0.05, two-way ANOVA followed by the LSD test).

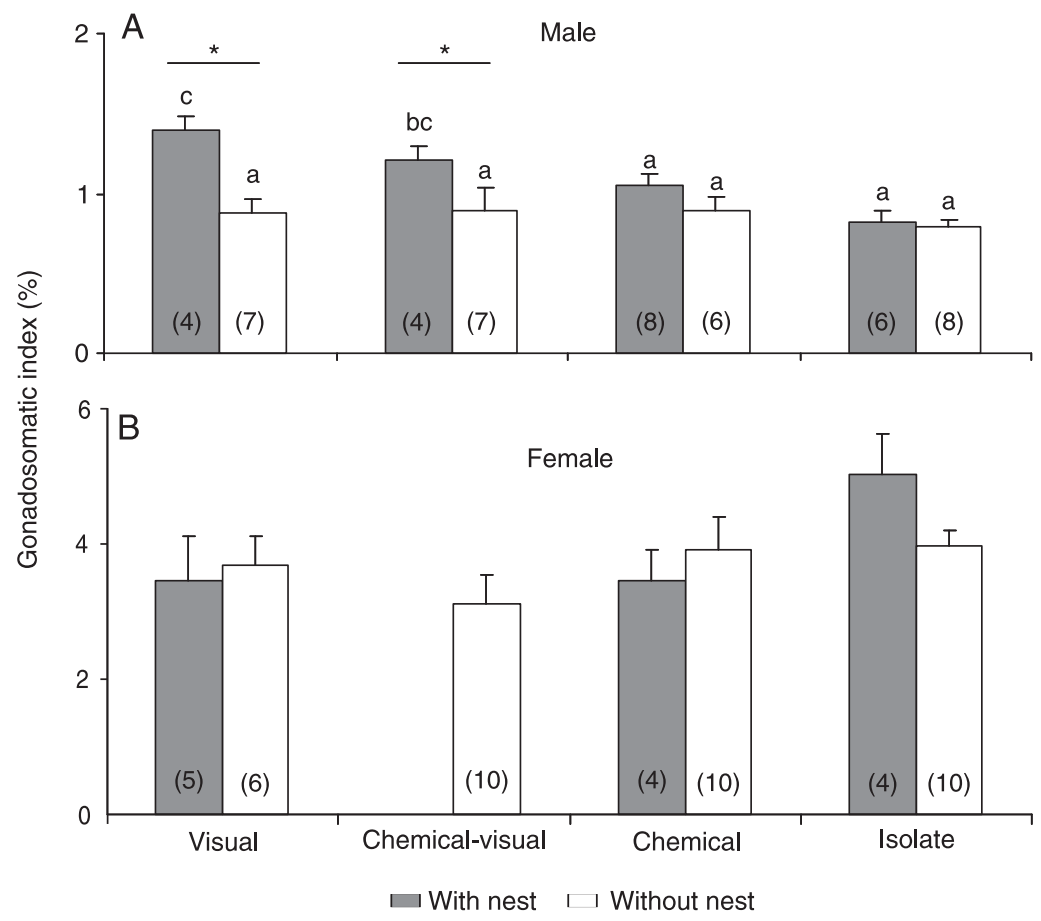

Figure 2. Gonadosomatic index (GSI) of Nile tilapia for each sensorial condition, with and without nests. Data are reported as means \pm SEM. Numbers of replicates are indicated within parentheses inside the respective bar. Lines over conditions compare GSI between fish with and without nesting in the same treatment: ${ }^{*} \mathrm{P}<$ 0.05 (LSD test). Letters compare means among sensorial groups for the same condition of nest building. Different letters indicate statistically significant differences ( ${ }^{*} P<0.05$, two-way ANOVA followed by the LSD test). 
built nest, with no male stimulation. This may occur when some structural components are absent in the environment, as reported for other cichlids $(6,26)$.

Nile tilapia reproductive behavior is plastic and adjustable to artificial environment. Reproduction can take place even in the absence of nest (27). Thus, the environmental structure of the present study might have stimulated females to build nest.

Nile tilapia courtship is a complex behavior (17), but in the present study the complete repertoire was not exhibited because males and females were physically separated. In fact, only undulation predominated and could be clearly observed, so that it was considered for the courtship analysis. Moreover, this behavior has already been considered for other fish species (e.g., 12,28).

Presence of a reproductive mate enhanced undulation in the $\mathrm{V}$ and $\mathrm{Ch}+\mathrm{V}$ treatments. Chemical communication alone was not sufficient to enhance the frequency of undulation, which was similar to the frequency among isolated animals. Visual cues, however, were more effective in stimulating courtship. In fact, female courtship behavior is elicited only by visual traits of the male and not by a multicomponent signal from different sensory modalities (29).

Visual contact with females increased male GSI. Males were in the same stage of maturation and, considering that spermatogenesis is continuous, increased GSI reflects an increase in semen production and volume (30). GSI enhancement is correlated positively with androgen hormones (31) and modulation of such hormones by visual stimulation was reported for other cichlid species $(32,33)$. Thus, visual pathways should be linked to hormonal control mechanisms in the Nile tilapia.

Chemical communication enhanced milt volume (sperm and seminal fluid) in Carassius auratus and Cyprinus carpio $(10,34,35)$. Pinheiro et al. (36) have shown that Nile tilapia males exposed to water with $17,20 \beta P\left(5 \times 10^{-9} \mathrm{M}\right)$ increased milt volume, spermatozoa motility and durability.
However, in the present study, chemical communication alone failed to affect male GSI. Such disagreement might be due to differences in 17,20ßP concentration in the water and/or time of exposition.

Spawning occurred at a low frequency in $\mathrm{V}$ and $\mathrm{Ch}+\mathrm{V}$, but not in $\mathrm{Ch}$ and Iso treatments, which demonstrated that watching males stimulates spawning in females. In Oreochromis genera, male-female contact occurs close to the final oocyte maturation period (6), and in other cichlids spawning occurs a few hours after ovulation (to Tilapia macrocephala) (37). Thus, visual contact with males can be one of the factors triggering ovulation followed by spawning in Nile tilapia, probably by hormonal stimulation (e.g., 33).

Although chemical communication did not affect Nile tilapia's reproductive behavior, rank signaling has been reported to be mediated by chemical cues in this species $(38,39)$. This suggests that cichlid visual and chemical information seems to be important at different moments of fish life. In fact, multimodal signs provide more reliable information for receiver fish, and could be an advantage for males and females to obtain more precise information about quality of the partners during mate choice (2). This multimodal role for vision and chemicals in Nile tilapia reproduction, however, needs further investigations.

\section{Acknowledgments}

The authors thank Mr. Carlos E. Souza and MSc. Roselene S.C. Ferreira for technical support; Dr. Sebastião R. Taboga for helping in the histological procedures; Dr. Francisco Langeani Neto for species identification; MSc. Francine Z. Mendonça, MSc. Thaís B. Carvalho and MSc. Fabrício B. Teresa for the insightful comments at the beginning of this study (all from Universidade Estadual Paulista (UNESP), São José do Rio Preto). We also thank Dr. Rosana Mattioli (Universidade Federal de São Carlos, UFSCar) for helpfull suggestions.

\section{References}

1. Liley NR, Stacey N. Hormones, pheromones and reproductive behavior in fish. In: Hoar WS, Randall DJ, Donaldson EM (Editors), Fish physiology. Vol IXB, Behavior and fertility control. New York: Academic Press; 1983. p 1-63.

2. Candolin U, Wong BBM. Mate choice. In: Maghagen $C$, Braithwaite V, Forsgren E, Kapoor BG (Editors), Fish behaviour. New Hampshire: Science Publishers; 2008. p 337376.

3. Satou M, Takeuchi H, Takei K, Hasegawa T, Okumoto N,

Ueda K. Involvement of vibrational and visual cues in eliciting spawning behavior in male himé salmon (landlocked red salmon, Oncorhynchus nerka). Anim Behav 1987; 35: 15561558.

4. Marshall JA. Influence of male sound production on oviposition in female Tilapia mossambica (Pisces, Cichlidae). Bull Ecol Soc 1972; 53: 29.

5. Amorim MCP, Vasconcelos RO. Variability in the mating calls of the Lusitanian toadfish Halobatrachus didactylus: 
cues for potential individual recognition. J Fish Biology2008; 73: 1267-1283.

6. Silverman HI. Effects of different levels of sensory contact upon reproductive activity of adult male and female Sarotherodon (Tilapia) mossambicus (Peters); Pisces: Cichlidae. Anim Behav 1978; 26: 1090.

7. Kramer DL. The role of androgens in the parental behaviour of the blue gourami, Trichogaster trichopterus (Pisces, Belontiidae). Anim Behav 1972; 20: 798-807.

8. Eaton RC, Farley RD. Spawning cycle and egg production of zebrafish, Brachydanio rerio, in the Laboratory. Copeia 1974; 1: 195-204.

9. Stacey N. Hormones, pheromones and reproductive behavior. Fish Physiol Biochem 2003; 28: 229-235.

10. Dulka JG, Stacey NE, Sorensen PW, Van der Kraak GJ. A steroid sex pheromone synchronizes male-female spawning readiness in goldfish. Nature 1987; 325: 251-253.

11. Douglas RH, Hawryshyn CW. Behavioural studies on fish vision: an analysis of visual capabilities. In: Douglas $\mathrm{RH}$, Djamgoz MBA (Editors), The visual system of fish. London: Chapman and Hall; 1990. p 373-418.

12. Venesky MD, Andraso GM, Ropski SJ. Behavior of male Kenyi Cichlids, Pseudotropheus lombardoi, in response to visual and olfactory cues from females. Bios 2005; 76: 7783.

13. Miranda A, Almeida OG, Hubbard PC, Barata EN, Canario AV. Olfactory discrimination of female reproductive status by male tilapia (Oreochromis mossambicus). J Exp Biol 2005; 208: 2037-2043.

14. Barata EN, Serrano RM, Miranda AN, Nogueira R, Hubbard $\mathrm{PC}$, Canário AVM. Putative pheromones from the anal glands of male blennies attract females and enhance male reproductive success. Anim Behav 2008; 75: 379-389.

15. Souza SMG, Lucion $A B$, Wassermann GF. Influence of $17 \alpha, 20 \beta$-hydroxy-4-pregnen-3-one injected into a post-ovulatory female on the reproductive behavior of male Nile tilapia (Oreochromis niloticus). Comp Biochem Physiol A 1998; 119A: 759-763.

16. Volpato GL, Duarte CR, Luchiari AC. Environmental color affects Nile tilapia reproduction. Braz J Med Biol Res 2004; 37: 479-483.

17. Gonçalves-de-Freitas E, Nishida SM. Sneaking behavior of the Nile tilapia. Bol Técn CEPTA 1998; 11: 71-79.

18. Gonçalves-de-Freitas $E$. Investimento reprodutivo e crescimento em machos de tilápia-do-Nilo. [PhD thesis]. Botucatu: Instituto de Biociências de Botucatu, UNESP; 1999.

19. Lowe-McConnell M. Breeding behavior patterns and ecological differences between tilapia species and their significance for evolution within the genus Tilapia (Pisces; Cichlidae). Proc Zool Soc Lond 1958; 132: 1-31.

20. Afonso LOB, Leboute EM. Métodos para sexagem visual de alevinos de tilápia nilótica, Oreochromis niloticus. Anais do IV Encontro Rio-Grandense de Técnicos em Aqüicultura. Porto Alegre: 1993. p 100-103.

21. Little DC, Coward K, Bhujel RC, Pham TA, Bromage NR. Effect of broodfish exchange strategy on the spawning performance and sex steroid hormone levels of Oreochromis niloticus broodfish in hapas. Aquaculture 2000; 186: 77-88.

22. Hannes RP, Franck D. The effect of social isolation on androgen and corticosteroid levels in a cichlid fish (Haplochromis burtoni) and in swordtails (Xiphophorus helleri). Horm Behav 1983; 17: 292-301.

23. Babiker MM, Ibrahim H. Studies on the biology of reproduction in the cichlid Tilapia nilotica (L.): gonadal maturation and fecundity. J Fish Biol 1979; 14: 437-448.

24. Volpato GL, Barreto RE. Environmental blue light prevents stress in the fish Nile tilapia. Braz J Med Biol Res 2001; 34 : 1041-1045.

25. Zar J. Biostatistical analysis. 4th edn. New Jersey: Prentice Hall; 1999.

26. Duponchelle F, Legendre M. Rapid phenotypic changes of reproductive traits in response to experimental modifications of spatial structure in Nile tilapia, Oreochromis niloticus. Aquat Living Resour 2001; 14: 145-152.

27. Mendonça FZ, Gonçalves-de-Freitas E. Nest deprivation and mating success in Nile tilapia (Teleostei: Cichlidae). Rev Bras Zool 2008; 25: 413-418.

28. Jaroensutasinee M, Jaroensutasinee K. Type of intruder and reproductive phase influence male territorial defence in wild-caught Siamese fighting fish. Behav Processes 2003; 64: 23-29.

29. Gonçalves DM, Barata EN, Oliveira RF, Canário AVM. The role of male visual and chemical cues on the activation of female courtship behavior in the sex-role reversed peacock blenny. J Fish Biol 2002; 61: 96-105.

30. Jalabert B, Zoar Y. Reproductive physiology in cichlid fishes, with particular reference to Tilapia and Sarotherodon. The Biology and Culture of Tilapias. Manila: ICLARM; 1984.

31. Yaron Z, Ilan Z, Bogomolnaya A, Vermaak JF. Steroid hormones in two Tilapia species: Oreochromis aureus and $O$. niloticus. Annals of International Symposium on Tilapia in Aquaculture. Israel: 1983. p 41-42.

32. Oliveira RF, Lopes M, Carneiro LA, Canario AV. Watching fights raises fish hormone levels. Nature 2001; 409: 475.

33. Oliveira RF, Gonçalves DM. Hormones and social behaviour of teleost fishes. In: Maghagen C, Braithwaite V, Forsgren E, Kapoor BG (Editors), Fish behaviour. New Hampshire: Science Publishers; 2008. p 61-150.

34. Stacey N, Zheng W, Cardwell J. Milt production in common carp (Cyprinus carpio): stimulation by a goldfish steroid pheromone. Aquaculture 1994; 127: 265-276.

35. Olsen KH, Sawisky GR, Stacey NE. Endocrine and milt responses of male crucian carp (Carassius carassius L.) to periovulatory females under field conditions. Gen Comp Endocrinol 2006; 149: 294-302.

36. Pinheiro MFM, Souza SMG, Barcellos LJG. Exposure to $17 \alpha, 20 \beta$-dihydroxy-4-pregnen-3-one changes seminal characteristics in Nile tilapia, Oreochromis niloticus. Aquac Res 2003; 34: 1047-1052.

37. Aronson LR. Factors influencing the spawning frequency in the female cichlid fish Tilapia macrocephala. Am Mus Novit 1951; 1484: 1-26.

38. Giaquinto PC, Volpato GL. Chemical communication, aggression, and conspecific recognition in the fish Nile tilapia. Physiol Behav 1997; 62: 1333-1338.

39. Gonçalves-de-Freitas E, Teresa FB, Gomes FS, Giaquinto $\mathrm{PC}$. Effect of water renewal on dominance hierarchy of the Nile tilapia. Appl Anim Behav Sci 2008; 112: 187-195. 